\title{
Fenologia da floração e biologia floral de bromeliáceas ornitófilas de uma área da Mata Atlântica do Sudeste brasileiro
}

\author{
CAIO GRACO MACHADO ${ }^{1,3}$ e JOÃO SEMIR ${ }^{2}$
}

(recebido: 7 de outubro de 2004; aceito: 2 de fevereiro de 2006)

\begin{abstract}
Flowering phenology and floral biology of some ornitophilous Bromeliaceae of an Atlantic forest area in southeastern Brazil). This study dealt with phenology and flower visitors of some Bromeliaceae species in an Atlantic Forest area at Parque Estadual Intervales, southeastern Brazil. The taxa studied belonged to the genera Tillandsia L. (3 spp.), Vriesea Lindl. (5 spp.), Aechmea Ruiz \& Pav. (3 spp.), Billbergia Thunb. (1 sp.) and Nidularium Lem. (2 spp.). Sample transects were established in areas with different succession stages, where the bromeliads were localized and marked. Flowering phenology surveys were made monthly. The bromeliad community showed a sequential flowering all along the year and most species flowered during the rainy season. The floral visitors were recorded by naturalistic observations. Eight hummingbird species visited the bromeliads flowers. Among them, Phaethornis eurynome Lesson and Thalurania glaucopis Gmelin were the most frequent visitors. Bromeliads were divided in two groups by similarity analysis of floral visitors (hummingbirds): a group represented by species visited by Trochilinae hummingbirds and another visited by Phaethornis eurynome (subfamily Phaethornithinae). The competition among bromeliad species for pollinators is reduced due to their spatial distribution and the flowering periods.
\end{abstract}

Key words - Atlantic Forest, Bromeliaceae, floral biology, hummingbirds, phenology

RESUMO - (Fenologia de floração e biologia floral de bromeliáceas ornitófilas de uma área da Mata Atlântica do Sudeste brasileiro). Foi investigada a fenologia e os visitantes florais de espécies da família Bromeliaceae em uma área de Mata Atlântica, no Parque Estadual Intervales, no Sudeste brasileiro. Os táxons estudados pertencem aos gêneros Tillandsia L. (3 spp.), Vriesea Lindl. (5 spp.), Aechmea Ruiz \& Pav. (3 spp.), Billbergia Thunb. (1 sp.) e Nidularium Lem. (2 spp.). Foram estabelecidas transecções amostrais em áreas com diferentes estádios sucessionais, onde foi registrada a localização dos indivíduos nos estratos da vegetação e realizados censos mensais da fenologia de floração. As bromeliáceas apresentaram padrão de floração seqüencial ao longo do ano, com maior número de espécies floridas na estação chuvosa. Os visitantes florais foram registrados por observações naturalísticas. Oito espécies de beija-flores visitaram as flores das bromélias. Destas, Phaethornis eurynome Lesson e Thalurania glaucopis Gmelim foram os visitantes mais freqüentes. A análise da similaridade dos beija-flores visitantes florais indicou a existência de dois conjuntos de espécies de bromeliáceas: o primeiro polinizado principalmente por espécies da sub-família Trochilinae e outro por Phaethornis eurynome (sub-família Phaethornithinae). A distribuição espacial diversa e, sobretudo os diferentes picos de floração foram os principais fatores que minimizaram a competição por polinizadores entre as espécies de Bromeliaceae estudadas.

Palavras-chave - beija-flores, biologia floral, Bromeliaceae, fenologia, Mata Atlântica

\section{Introdução}

Bromeliaceae está entre as poucas famílias em que a polinização por vertebrados predomina sobre a polinização por insetos (Sazima et al. 1989). Sick (1984) sugere que a diversificação das famílias Bromeliaceae e Trochilidae tenha se processado paralelamente, pois esta última contém os agentes polinizadores mais

\footnotetext{
1. Universidade Estadual de Feira de Santana, Departamento de Ciências Biológicas, Km 03 - BR 116, 44031-460 Feira de Santana, BA, Brasil.

2. Universidade Estadual de Campinas, Departamento de Botânica, Caixa Postal 6109, 13083-970 Campinas, SP, Brasil.

3. Autor para correspondência: graco@uefs.br
}

importantes para as bromélias. Essa idéia tem sido corroborada por diversos estudos que apontam os beijaflores como vetores de pólen de cerca de $85 \%$ das bromeliáceas nas diferentes comunidades investigadas, sendo as demais espécies visitadas por morcegos e, em menor quantidade, abelhas (Snow \& Snow 1980, 1986, Snow \& Teixeira 1982, Gardner 1986, Fischer \& Araujo 1995, Sazima et al. 1995, 1996, Canela \& Sazima 2003, Araujo et al. 2004).

A fenologia e polinização de Bromeliaceae têm sido relativamente pouco investigadas. O padrão fenológico de uma comunidade vegetal é relevante no estudo da interação planta-animal, pois propicia importante ferramenta para o entendimento da reprodução das plantas e da organização espaço-temporal dos recursos disponíveis no ambiente aos animais associados 
(Morellato \& Leitão Filho 1992, Talora \& Morellato 2000). A floração seqüencial das bromeliáceas em uma região pode ser de extrema importância para a manutenção dos agentes polinizadores na área, contribuindo para a eficiência no sistema de polinização de espécies ornitófilas da comunidade (Waser \& Real 1979, Feinsinger 1983, Araujo et al. 1994, Fischer \& Araujo 1995).

Este estudo objetivou investigar o padrão fenológico de floração e atributos florais de bromélias ornitófilas em uma área da Mata Atlântica de região serrana e a utilização diferencial destes recursos pelas espécies de beija-flores.

\section{Material e métodos}

Este estudo foi realizado no Parque Estadual Intervales (PEI), em Ribeirão Grande, SP, Brasil. O PEI situa-se a $24^{\circ} 12^{\prime}$ - $24^{\circ} 25^{\prime} \mathrm{S}$ e $48^{\circ} 03^{\prime}-48^{\circ} 30^{\prime} \mathrm{W}$, com área de 49.000 ha. Os registros foram feitos na região da sede administrativa do PEI, a 950 m de altitude, de setembro de 1994 a março de 1996, com 19 visitas mensais de oito a 20 dias cada. O relevo na área é do tipo "montanha com vales profundos" (Ponçano 1981). A vegetação é típica da zona ecotonal dos domínios Tropical Atlântico e dos Planaltos de Araucária. Devido ao relevo e aos estádios sucessionais diversos, existem diferenças entre as florestas que ocorrem nos vários ambientes da região. Para maior detalhamento sobre a vegetação local veja Nascimento (1994). O clima é classificado como $C f b$ (Köepen 1948). A precipitação anual é entorno de $1.800 \mathrm{~mm}$, com pequenas diferenças sazonais, ocorrendo uma estação chuvosa, de outubro a março, e outra subseca, de abril a setembro. A temperatura média anual é de $22^{\circ} \mathrm{C}$, com mínima registrada de $0^{\circ} \mathrm{C}$ e máxima de $32{ }^{\circ} \mathrm{C}$ (Machado 1999).

Foram estabelecidos sete transectos (com extensões de $1.500 \mathrm{~m}, 600 \mathrm{~m}, 600 \mathrm{~m}, 2.400 \mathrm{~m}, 600 \mathrm{~m}, 1.500 \mathrm{~m}$ e $800 \mathrm{~m}$, totalizando $8.000 \mathrm{~m}$ ), onde foram amostradas áreas de ambientes distintos, determinados pelo relevo (encostas e vales). A área de amostragem $\left(48.000 \mathrm{~m}^{2}\right)$ foi calculada a partir do comprimento dos transectos multiplicado por suas larguras, visto que a amostragem era feita até três metros de cada lado do eixo dos transectos.

Das espécies de Bromeliaceae ocorrentes na área, foram estudadas as que floresceram no período de estudo e consideradas ornitófilas.

No campo, as bromeliáceas foram identificadas após formação da inflorescência. Muitas espécies apresentam indivíduos que ocorrem agregados, formando densas touceiras. Nesse caso, como procedeu Fischer (1994), foi considerado que cada inflorescência correspondia a um indivíduo.

A determinação da fenofase de floração foi feita através de registros mensais, quando foram anotados o número de indivíduos floridos de cada espécie, o estrato da vegetação em que estavam estabelecidos (solo, sub-bosque e dossel) e o respectivo hábito (terrestre, epifítico ou facultativo).

As espécies de bromélias foram classificadas como heliófilas quando ocorriam preferencialmente em locais com alto grau de luminosidade, com incidência direta de luz solar, ou esciófilas, quando se desenvolviam em ambientes sombreados e de luz difusa (Fischer \& Araujo 1995).

A classificação dos padrões fenológicos seguiu Newstrom et al. (1994) e a categorização quanto à síndrome de polinização foi feita através da análise dos atributos florais (Faegri \& Pij1 1980). Neste estudo, considerou-se como pico de floração o período no qual mais que $50 \%$ dos indivíduos amostrados de cada espécie estavam floridos.

Durante o período de floração foram registrados (em no mínimo três indivíduos diferentes) o número de flores abertas por dia, o período de disponibilidade da flor (o período em que a flor permanece aberta, disponível aos visitantes, desde sua antese até a senescência - em algumas espécies as flores podem durar mais que um dia, apresentando fechamento e abertura das flores, uma ou mais vezes, entre o período de antese e senescência), a duração (em dias) das flores, o comprimento do tubo da corola, o período de deiscência das anteras com o pólen disponível (Dafni 1992) e o período de receptividade do estigma (Kaerns \& Inouye 1993), além da coloração do cálice, corola e brácteas. A coleta de néctar e determinação de seu volume foi feita com uso de microsseringa ou microcapilares graduados, em flores previamente isoladas com sacos de papel, em intervalos de duas horas durante todo o período de abertura da flor. A concentração de solutos no néctar (açúcares hidrossolúveis) foi determinada com o uso de refratômetro de bolso.

As observações dos beija-flores visitantes foram feitas com auxílio de binóculos 8 X 35 ou à vista desarmada. As sessões foram feitas da aurora ao crepúsculo ou até o fechamento ou a senescência das flores. Para o registro dos beija-flores visitantes foi adotado o método de observação indivíduo-focal (Altmann 1974), com no mínimo três repetições para cada espécie. A variação do número de horas de observação em cada espécie decorreu do período de disponibilidade da flor, número de dias de duração da flor e diferenças nos horários da aurora e crepúsculo nas diferentes estações do ano. Em cada sessão de observação-focal, foram registradas quais espécies de beija-flor visitavam as flores das bromeliáceas, o horário e o número de visitas (considerou-se "visita" toda vez que um beija-flor se alimentava do néctar de uma flor) e o local de impregnação de pólen nas aves. Todas as ocorrências de agonismo intra ou interespecífica entre os beija-flores foram registradas. A identificação das aves foi feita em campo e a classificação seguiu Sick (1984).

Para determinar a similaridade entre a guilda de beijaflores polinizadores associada às espécies de bromeliáceas estudadas, foi utilizado o Índice de Jaccard (Magurran 1988). Todos os cálculos estatísticos seguiram as determinações 
de Sokal \& Rohlf (1981), sendo testada a distribuição normal dos dados. No caso do volume e concentração de néctar produzido foram excluídos os "out liers", uma vez que, em algumas flores, a presença de muco ou água de chuva acumulada, causaram aumento do volume e diluição do néctar. Desta forma, todas as análises foram paramétricas. Utilizouse a correlação de Spearman para correlacionar comprimento de bico de beija-flor e de tubo da corola, assim como frequiência de visita de beija-flor e produção de néctar pela flor. A análise de agrupamento foi feita pelo método das distâncias médias entre os grupos (UPGMA) sobre o coeficiente de distância métrica Euclidiana. Utilizou-se nestas análises o pacote estatístico SPSS - Statistical Package for Social Sciences (SPSS 1983).

\section{Resultados}

Quatorze espécies de bromeliáceas ornitófilas floresceram durante este estudo (tabela 1), sendo cinco pertencentes à sub-família Bromelioideae (gêneros Nidularium, Billbergia e Aechmea) e as demais à subfamília Tillandsioideae (Vriesea e Tillandsia). Outras espécies de bromélias ornitófilas podem ocorrer na área de estudo, como Vriesea vagans L.B. Smith, Vriesea friburguensis Mez e Canistrum lindenii (Regel) Mez, porém não floresceram durante o período de coletas de dados. Apesar de Vriesea philippocoburgii não ter ocorrido dentro da área amostral, foram registrados dados sobre sua fenologia, biologia floral e sobre os seus visitantes florais, pois é uma espécie comum na região.

Das espécies de bromélias estudadas, nenhuma apresentou hábito exclusivamente terrestre (tabela 1) e mesmo as de hábito facultativo tenderam ao epifitismo, com raros indivíduos crescendo junto ao solo, muitas vezes sobreviventes de quedas de galhos de estratos mais altos da vegetação, nos quais estavam estabelecidas. Nidularium rubens foi a espécie mais freqüentemente observada estabelecendo-se diretamente sobre o solo.

Nove espécies foram classificadas como heliófilas (tabela 1) e ocorreram preferencialmente nos estratos mais altos da vegetação ou, quando em estratos mais baixos, em locais mais ensolarados, como clareiras e bordas de mata. As espécies esciófilas ocorreram nos estratos mais baixos e dentro do sub-bosque; quando presentes no dossel, ocorriam dentro das copas densas, que proporcionavam ambiente sombreado.

Tabela 1. Bromeliáceas ornitófilas estudadas na região da sede do Parque Estadual Intervales, Ribeirão Grande, SP, seus hábitos, tolerância à luminosidade e as espécies de beija-flores que visitaram suas flores ( $\mathrm{TG}_{\mathrm{G}}=$ Thalurania glaucopis Gmelin; $\mathrm{C}_{\mathrm{R}}=$ Clytolaema rubricauda Boddaert $\mathrm{PE}=$ Phaethornis eurynome Lesson; $\mathrm{Av}=$ Amazilia versicolor Vieillot; $\mathrm{C}_{\mathrm{A}}=$ Chlorostilbon aureoventris Orbigny \& Lafresnaye; $\mathrm{LA}=$ Leucochloris albicollis Vieillot; $\mathrm{AN}=$ Anthracothorax nigricollis Vieillot; MF = Melanotrochilus fuscus Vieillot).

Table 1. Ornitophilous species of Bromeliceae at the Parque Estadual Intervales (Ribeirão Grande, SP, Brasil), their habits, tolerance to light and visitor humminbirds $\left(\mathrm{T}_{\mathrm{G}}=\right.$ Thalurania glaucopis $\mathrm{Gmelin} ; \mathrm{C}_{\mathrm{R}}=$ Clytolaema rubricauda Boddaert; $\mathrm{PE}=$ Phaethornis eurynome Lesson; $\mathrm{Av}=$ Amazilia versicolor Vieillot; $\mathrm{CA}_{\mathrm{A}}=$ Chlorostilbon aureoventris Orbigny \& Lafresnaye; $\mathrm{LA}=$ Leucochloris albicollis Vieillot; AN = Anthracothorax nigricollis Vieillot; MF = Melanotrochilus fuscus Vieillot).

Espécies

Hábito

facultativo

Aechmea nudicaulis (L.) Griseb. Aechmea organensis Wawra Aechmea ornata Lodd. Billbergia amoena Lodd. Nidularium innocentii Lem. Nidularium rubens $\mathrm{Mez}$ Tillandsia geminiflora Brongn. Tillandsia stricta Soland. Tillandsia tenuifolia L. Vriesea altodaserrae L.B.Sm. Vriesea carinata Wawra Vriesea flammea L.B.Sm. Vriesea incurvata Gaudich. Vriesea philippocoburgii Wawra facultativo

facultativo

epifítico

facultativo

facultativo

epifítico

epifítico

epifítico

facultativo

facultativo

epifítico

epifítico

facultativo

Tolerância à luminosidade

Espécies de beija-flores visitantes florais

heliófila

heliófila

heliófila

esciófila

esciófila

esciófila

heliófila

heliófila

heliófila

heliófila

esciófila

heliófila

esciófila

heliófila
TG

TG, $\mathrm{CR}_{\mathrm{R}}$

PE, TG

PE

PE

PE

Av, CA, LA

Av, LA

LA

Tg, Pe, Av, LA, MF, CA, An, CR PE

PE, LA

$\mathrm{PE}, \mathrm{MF}$

TG 
A comunidade de bromélias apresentou floração seqüencial e contínua (figura 1). Todas as espécies apresentaram padrão anual de floração e, quanto à duração da fenofase de floração, a maioria foi do tipo curta (figura 1). Foi verificado em Aechmea organensis, Vriesea incurvata e V. philippocoburgii que o período de floração foi mais extenso; nas duas primeiras espécies, a fenofase de floração individual é curta, porém os diferentes indivíduos vão se sucedendo em floração, enquanto em $V$. philippocoburgii a floração individual é extensa, com grande quantidade de flores por indivíduo ( $\bar{x}=146,78 \pm 13,46 ; n=10)$, mas com um número baixo delas abertas por dia $(\bar{x}=4,40 \pm 2,03 ; n=10)$.

O maior número de espécies $(n=10)$ floresceu na estação chuvosa, entre outubro e março (figura 1 ). $\mathrm{O}$ número total de indivíduos floridos nos transectos amostrais variou durante o ano (figura 2), sendo significativamente menor durante a estação subseca $(P \leq 0,05)$. Os picos com maior número de indivíduos floridos nos meses de junho, agosto e setembro foram conseqüência do período de pico de floração de V. carinata (junho) e T. stricta (agosto e setembro), espécies abundantes na área de estudo.
Tillandsia stricta e T. geminiflora apresentaram flores que perduraram por três dias enquanto T. tenuifolia, Nidularium rubens e $N$. innocentii, flores que duraram dois dias. Nas Tillandsia ocorreu o fechamento da flor no final do dia e abertura na manhã seguinte. Em Nidularium as flores permaneceram com o ápice das pétalas fechado, não expondo anteras e estigma. As demais espécies estudadas apresentaram flores com duração de apenas um dia (tabela 2). Todas as bromélias estudadas apresentaram antese diurna, por volta 4 e 6 h da manhã e senescência entre 17 e $20 \mathrm{~h}$ (tabela 2). No caso de Nidularium, considerou-se como período de disponibilidade o período de produção de néctar do início da manhã, por volta das 05 h e 30 min., quando as anteras já estavam abertas e os grãos de pólen expostos e facilmente removíveis, até por volta das $12 \mathrm{~h}$ (tabela 2).

Nas espécies estudadas, o volume médio de néctar foi $132,0 \pm 138,7 \mathrm{~mL}$ por flor. $\mathrm{O}$ alto desvio padrão ocorreu em algumas espécies que secretaram néctar em grande quantidade, como Vriesea altodaserrae e $V$. incurvata (tabela 2). A concentração do néctar variou de $20 \%$ a $30 \%$ (tabela 2 ), com média de $25,7 \pm 3,8 \%(n=14)$. Foi significativa a correlação entre

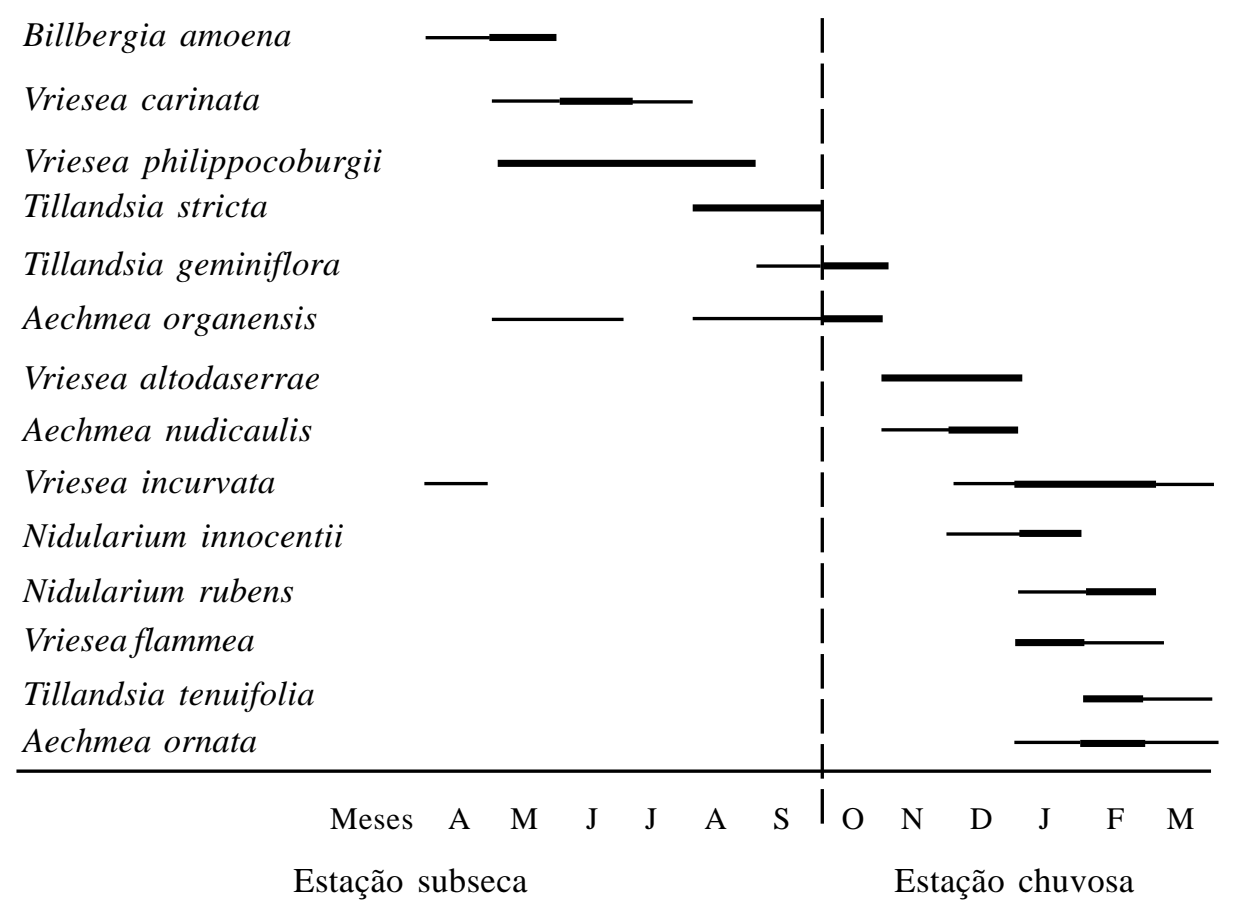

Figura 1. Fenologia de floração de 14 espécies de bromeliáceas que ocorrem na região da sede do Parque Estadual Intervales, Ribeirão Grande, SP, entre abril de 1995 e março de 1996. A linha simples representa o período total de cada florada e a mais grossa, o pico de floração.

Figure 1. Floral phenology of 14 Bromeliaceae species of the Parque Estadual Intervales (Ribeirão Grande, SP, Brasil), April/ 1995-March/1996. (Fine line = flowering period; thick line = flowering peak). 


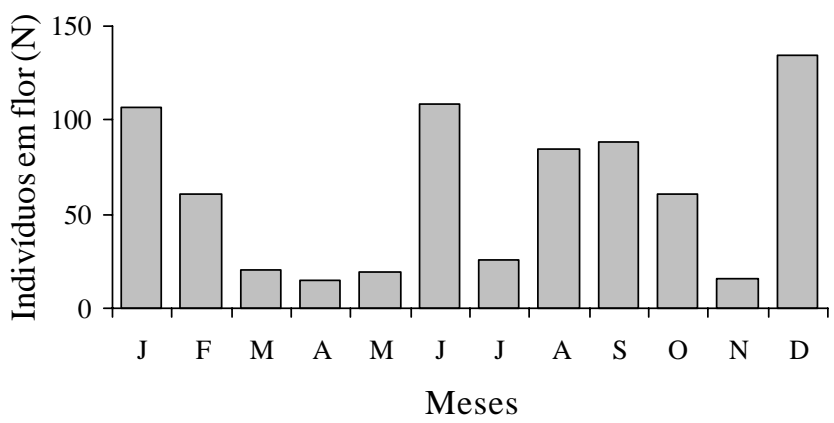

Figura 2. Número total de indivíduos de bromélias floridos, registrados mensalmente nos transectos amostrais estabelecidos na região da sede administrativa do Parque Estadual Intervales, Ribeirão Grande, SP, durante 1995.

Figure 2. Number of flowering individuals of Bromeliaceae recorded monthly in the sampled transect of the Parque Estadual Intervales (Ribeirão Grande, SP, Brasil), in 1995.

comprimento do tubo e volume de néctar produzido nas espécies estudadas $(r=0,51 ; P \leq 0,05 ; n=14)$. A correlação entre tamanho do tubo da corola e concentração de néctar das bromélias foi positiva, mas não significativa $(r=0,21 ; P \geq 0,05 ; n=14)$.

Os tubos das corolas de Nidularium rubens e $N$. innocentii são brancos e longos. As flores se desenvolvem dentro da roseta, em posição terminal ou axial, imersas na água acumulada. $O$ contraste com o vermelho das folhas mais internas as tornam conspícuas. O estigma se tornou receptivo duas horas após o início de produção de néctar da flor e permaneceu receptivo até a sua senescência, no segundo dia de duração da flor.

Aechmea ornata e A. organensis têm flores violeta a lilás, enquanto em $A$. nudicaulis estas são amarelas. Em $A$. ornata, as flores contrastam com as brácteas do escapo, que são grandes e vermelhas. Em A. organensis há contraste com escapo e brácteas dos pedúnculos, de coloração vinácea. Por sua vez, o contraste das flores amarelas de Aechmea nudicaulis se dá com as grandes brácteas vermelhas do escapo. Em todas as espécies, a liberação do pólen das anteras ocorreu logo após a antese, enquanto o estigma se tornou receptivo em torno de três horas depois.

Billbergia amoena tem corola amarela, ligeiramente translúcida, com o ápice esverdeado, contrastando com grandes brácteas vermelhas. Cada inflorescência produziu cinco ou seis flores e metade delas abriu no mesmo dia e as restantes, dois dias depois. Verificou-se que em algumas flores $(n=15)$ de diversas inflorescências $(n=10)$, não houve a produção de néctar, apesar dos nectários desenvolvidos próximo ao ovário. Os grãos de pólen amadureceram após a antese da flor, se desprendendo facilmente das anteras, enquanto o estigma, assim como nas espécies congêneres, se tornou receptivo cerca de três horas após a antese.

Tillandsia stricta, T. geminiflora e T. tenuifolia possuem flores relativamente pequenas, azul-arroxeadas nas duas primeiras e brancas na última, todas com brácteas rosadas. Nessas espécies as anteras abriramse logo após a antese, liberando grãos de pólen, mas a receptividade do estigma foi detectada no segundo dia, após sua abertura e no caso de Tillandsia stricta e T. geminiflora, também no terceiro dia de abertura da flor.

As corolas das flores das espécies de Vriesea são de coloração amarelo intenso, contrastando com o vermelho das sépalas, brácteas e escapo, com exceção de $V$. flammea, cuja corola branca é conspícua pelo contraste do cálice, brácteas e escapo de coloração vermelho-vinácea. As flores de Vriesea secretaram néctar com concentração média de $24 \%$. Em todas elas, as anteras se abriram cerca de uma hora após a antese, liberando os grãos de pólen. O estigma se tornou receptivo, em todas as espécies, logo após a antese da flor.

Oito espécies de bromeliáceas apresentaram uma produção maior de néctar no período da manhã (figura 3). Aechmea nudicaulis, Vriesea carinata e Tillandsia geminiflora produziram néctar mais uniformemente ao longo do dia, sendo que a última apresentou dois picos de maior produção, um pela manhã e outro pela tarde. Tillandsia stricta teve uma maior produção no período da tarde, enquanto Vriesea flammea e $V$. altodaserrae produziram mais néctar das 10 às $14 \mathrm{~h}$ (figura 3 ).

Quanto à correlação entre produção de néctar e à frequiência de visitas de beija-flores ao longo do dia, Aechmea nudicaulis, Billbergia amoena, Tillandsia geminiflora, T. stricta, T. tenuifolia, Vriesea carinata, $V$. incurvata, V. flammea e V. philippocoburgii apresentaram correlação positiva e estatisticamente significativa $(P \leq 0,05)$ (respectivamente: $r=0,92$; $r=0,85 ; r=0,88 ; r=0,96 ; r=0,86 ; r=0,64 ; r=0,46$; $r=0,73$ e $r=0,83)$. Aechmea organensis, A. ornata, Nidularium innocentii e $N$. rubens apresentaram correlação positiva, porém não significativa $(P \geq 0,05)$ (respectivamente: $r=0,39 ; r=0,35 ; r=0,37 \mathrm{e} r=0,27$ ); por sua vez, $V$. altodaserrae apresentou correlação negativa não significativa $(r=-0,40 ; P \geq 0,05)$.

Oito espécies de beija-flores foram registradas 


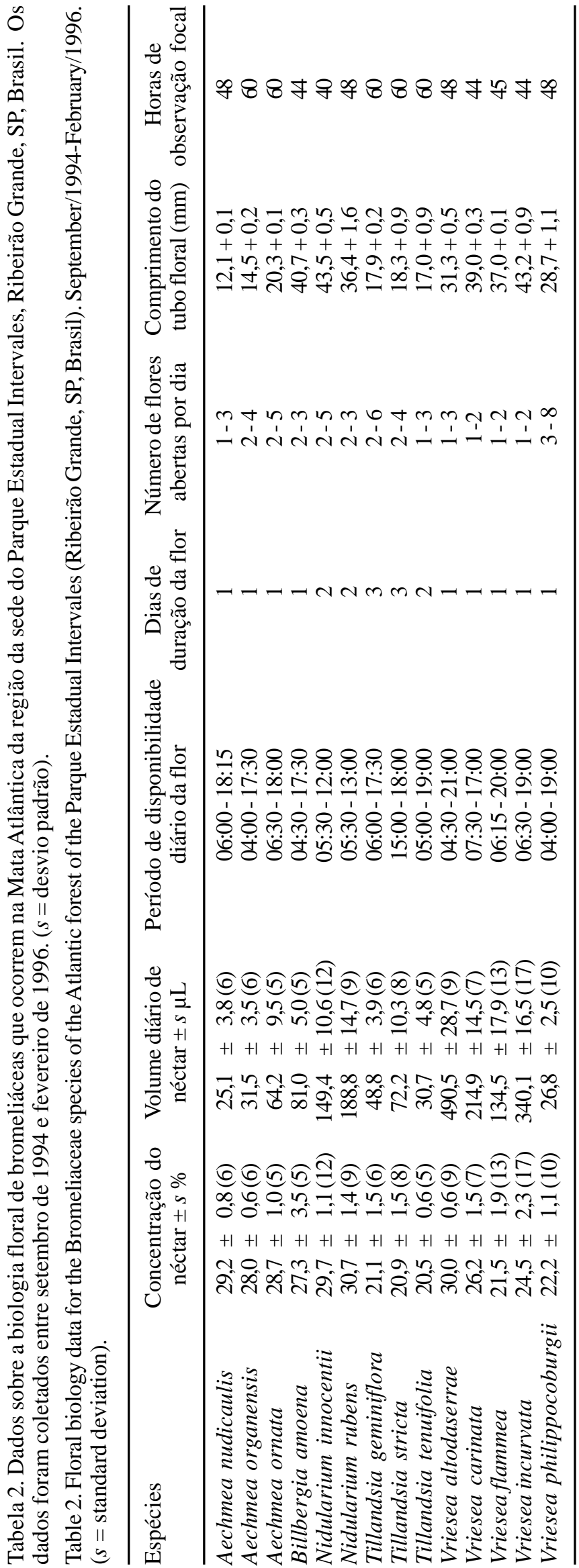

visitando as flores das bromeliáceas (tabela 1, figura 3). Desses, apenas cinco delas ocorreram na região ao longo do ano todo (Phaethornis eurynome, Thalurania glaucopis, Amazilia versicolor, Leucochloris albicollis e Chlorostilbon aureoventris). As outras três espécies estiveram ausentes em toda a estação subseca ou em grande parte dela, como Anthracothorax nigricollis, presente de outubro a março, Melanotrochilus fuscus, presente de outubro até abril e Clytolaema rubricauda, de outubro a maio.

Todas as espécies efetuaram visitas legítimas pela frente e tocando as partes reprodutivas das flores, não tendo sido observadas tentativas de perfuração da base da flor para pilhar néctar. A correlação entre comprimento dos bicos de beija-flores e comprimento dos tubos das corolas das bromeliáceas que visitam não foi significativa $(r=0,41 ; P \geq 0,05 ; n=29)$.

As únicas espécies de beija-flores que visitaram mais de cinco espécies de bromélias foram Phaethornis eurynome, Thalurania glaucopis e Leucochloris albicollis (tabela 1). Phaethornis eurynome visitou oito espécies, sendo que em quatro delas foi único vetor de pólen (Billbergia amoena, Nidularium rubens, $N$. innocentii e Vriesea carinata); as demais espécies foram visitadas também por outros troquilídeos, porém nestas, $P$. eurynome foi o visitante mais frequiente (V. flammea, V. incurvata e A. ornata) ou o segundo mais frequiente ( $V$. altodaserrae). Esse beija-flor tendeu a forragear nas espécies do sub-bosque e na porção inferior das copas (Billbergia amoena). Na maioria das espécies de bromélias que explorou as visitas às flores foram em intervalos de 40 minutos a uma hora. Exceção ocorreu durante a floração de Vriesea altodaserrae, quando permaneceu próximo à área de observação, entre as 10 e $14 \mathrm{~h}$, período em que se verificou nesta a produção de maior volume de néctar (figura 3 ). O local de deposição de pólen das bromélias visitadas em Phaethornis eurynome foi o bico, sendo que apenas o pólen de Billbergia amoena foi depositado na fronte.

Thalurania glaucopis exibiu comportamento territorialista, permanecendo próxima a área onde havia plantas floridas. Visitou cinco espécies de bromélias (tabela 1), sendo o único visitante de Aechmea nudicaulis e Vriesea philippocoburgii. Foi também a espécie com maior número de visitas em Aechmea organensis e Vriesea altodaserrae. Nessa última, o pólen foi depositado na fronte da ave, porém o local com maior freqüência de impregnação foi o bico, embora em Vriesea philippocoburgii o pólen também foi depositado no vértice da ave. Esse troquilídeo ocorreu tanto em áreas mais abertas como no interior da mata, 


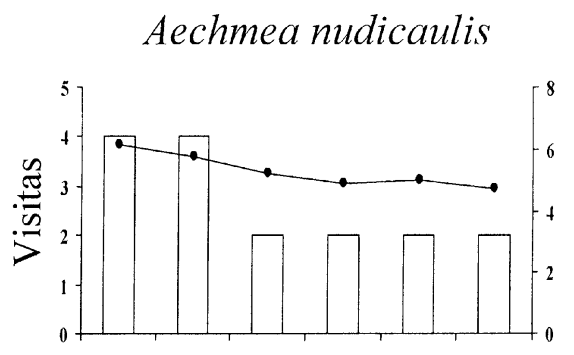

Billbergia amoena
Aechmea organensis

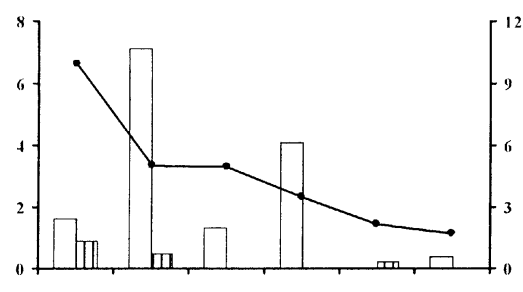

Nidularium rubens
Aechmea ornata

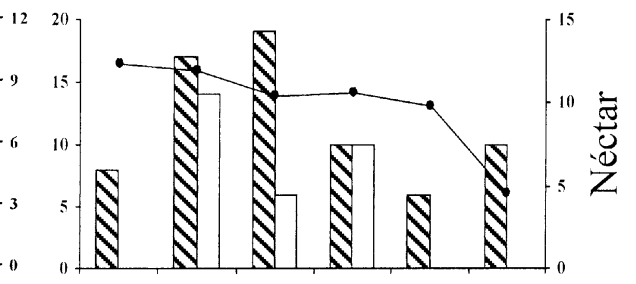

Nidularium innocentii

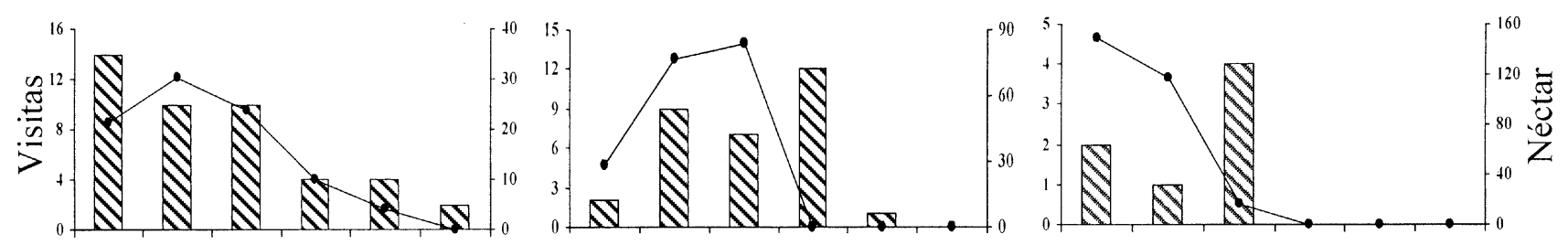

Tillandsia geminiflora

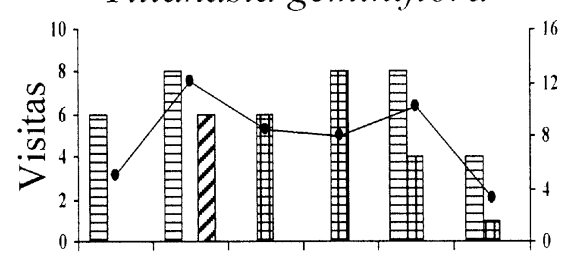

Tillandsia stricta

Tillandsia tenuifolia
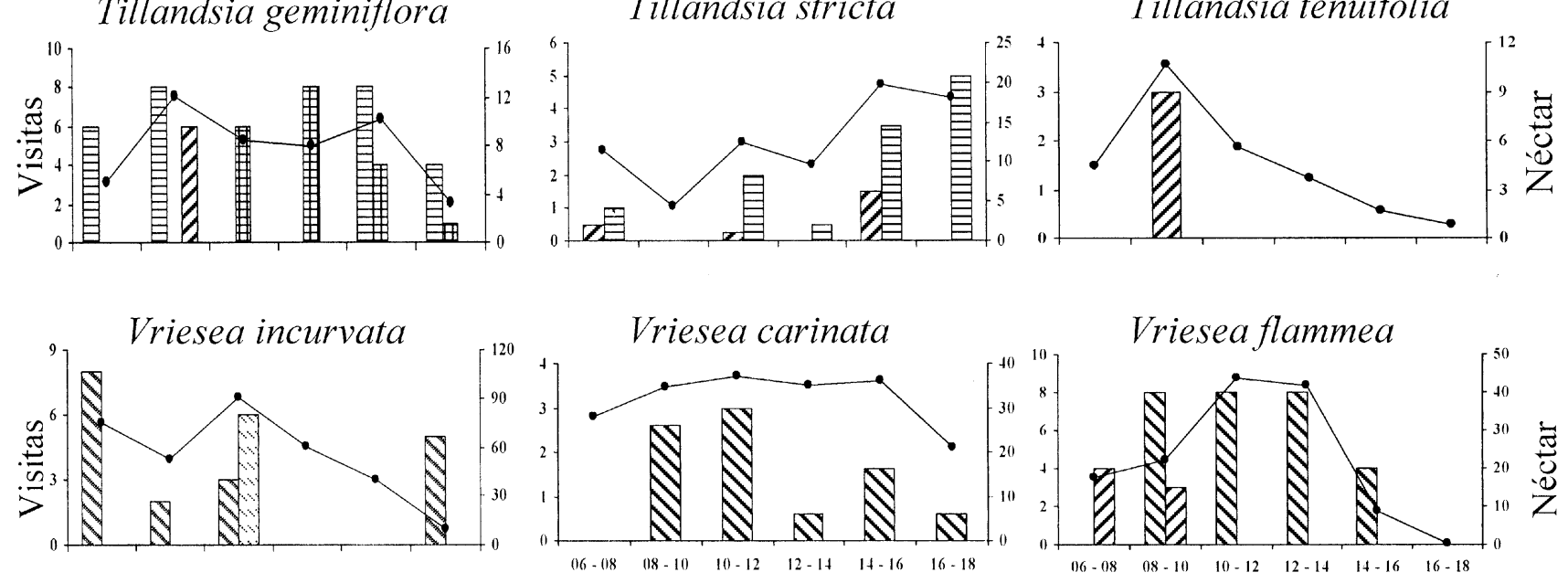

Vriesea carinata

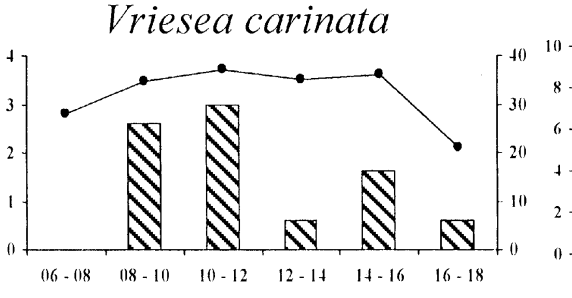

horas

Vriesea philippocoburgii

Vriesea altodaserrae

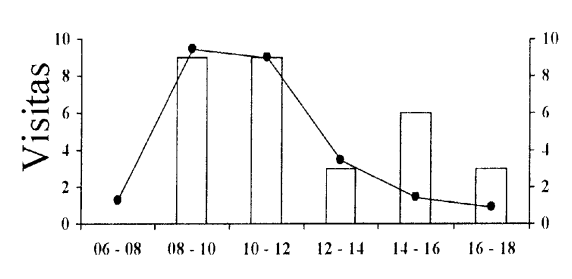

horas

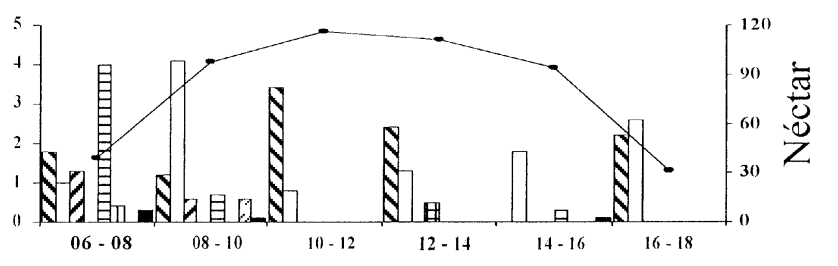

horas

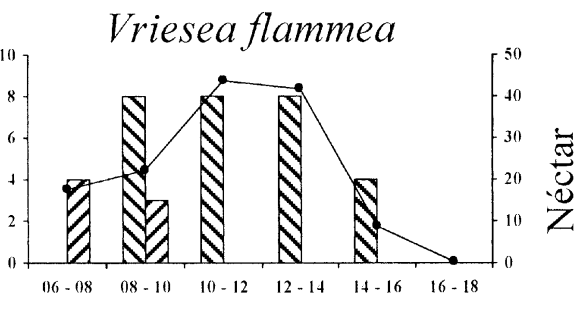

horas

Figura 3. Volume médio de néctar $(\mu \mathrm{L})$ produzido por flores de bromeliáceas ornitófilas e número médio de visitas de beija-flores ao longo do dia $(n=3)$ no Parque Estadual Intervales, Ribeirão Grande, SP.

Figure 3. Mean nectar volume $(\mu \mathrm{L})$ in the flowers of ornitophilous bromeliaceae, and hummingbirds visits during the day $(n=3)$ in the Parque Estadual Intervales (Ribeirão Grande, SP, Brasil).

( $\mathbb{Q}=$ Phaethornis eurynome; $\mathbb{Z}=$ Leucochloris albicollis; 目 = Amazilia versicolor; $⿴=$ Melantrochylus fuscus; $\square=$ Thalurania glaucopis; 慻 = Chlorostilbon aureoventris; 四 = Clytolaema rubricauda $\boldsymbol{\square}=$ Anthracothorax nigricollis; $-\bullet-=$ Volume de néctar). 
onde foi mais freqüente.

Leucochloris albicollis foi observada mais freqüentemente em áreas abertas, capoeiras e matas de vegetação secundária recente e antiga, porém também pôde ser avistado em área de mata primária, onde forrageou em estratos mais altos da vegetação. Visitou Vriesea altodaserrae, V. flammea e todas as três espécies de Tillandsia estudadas, sendo o visitante exclusivo de $T$. tenuifolia (tabela 1). Todas essas espécies tiveram seu pólen depositado no bico de Leucochloris albicollis.

Amazilia versicolor, espécie típica de áreas abertas, foi observada em capoeiras e áreas de mata secundária, sendo a principal visitante de Tillandsia stricta e T. geminiflora. Exibiu comportamento agonístico, expulsando outros visitantes, principalmente durante os períodos de maior produção de néctar em Tillandsia.

A partir do agrupamento ("cluster"), elaborado com os valores dos índices de similaridade (Jaccard) de uso das espécies de bromeliáceas pelas diferentes espécies de beija-flores, observou-se dois grandes conjuntos de espécies de bromélias (figura 4), sendo o primeiro composto por dois sub-conjuntos: o primeiro (Vriesea philippocoburgii, Aechmea nudicaulis e $A$. organensis), cujo único ou principal visitante floral foi Thalurania glaucopis e o segundo (Tillandsia geminiflora, T. stricta, T. tenuifolia e $V$. altodaserrae), cujas espécies foram visitadas principalmente por Amazilia versicolor, Leucochloris albicollis, Chlorostilbon aureoventris (tabela 1). O segundo conjunto de bromélias foi formado pelas espécies que utilizam Phaethornis eurynome como seu único vetor de pólen (Nidularium rubens, $N$. innocentii, Vriesea carinata e Billbergia amoena) ou como o mais frequiente agente polinizador (Vriesea incurvata, $V$. flammea e Aechmea ornata) (tabela 1, figura 4).

\section{Discussão}

Em estudos realizados com bromeliáceas ornitófilas em diferentes áreas de Mata Atlântica da planície litorânea no Estado de São Paulo foram registradas 22 espécies em Caraguatatuba (Buzato et al. 2000), 15 espécies em Picinguaba (Araujo 1996) e 24 espécies na Juréia (Araujo et al. 2004); na Serra do Mar, ainda no Estado de São Paulo, Buzato et al. (2000) registraram 12 espécies no município de Cunha, com altitude de cerca de $1.000 \mathrm{~m}$, e sete espécies em Campos do Jordão (ca. de $1.500 \mathrm{~m}$ de altitude), de bromélias ornitófilas. Estes dados corroboram Snow \& Snow (1986), que sugerem que a maior diversidade e riqueza de espécies de bromeliáceas ocorrem em áreas de pouca altitude. Benzing (1980) e Reitz (1983) consideram que as baixas temperaturas de inverno, que ocorrem em regiões de altitude maior, podem ser um fator limitante para o estabelecimento de várias espécies de bromélias.

Na comunidade estudada, o padrão de floração da comunidade de bromélias ornitófilas foi sequencial e contínuo. Estudos realizados na Mata Atlântica do Sudeste brasileiro têm constatado que as bromeliáceas formam o maior grupo de plantas ornitófilas (em riqueza de espécies) na comunidade e que também apresentam o mesmo padrão de floração (Araujo et al. 1994, Buzato et al. 2000). A disponibilidade de flores ornitófilas ao longo do ano possibilita a permanência beija-flores polinizadores na área. Isso propicia uma maximização do sucesso reprodutivo das espécies de plantas envolvidas, pois caso haja deslocamentos populacionais destas aves, devido a uma pausa na oferta de recursos, as primeiras espécies de plantas ornitófilas que florirem não encontrarão disponíveis seus agentes polinizadores (Poulin et al. 1992).

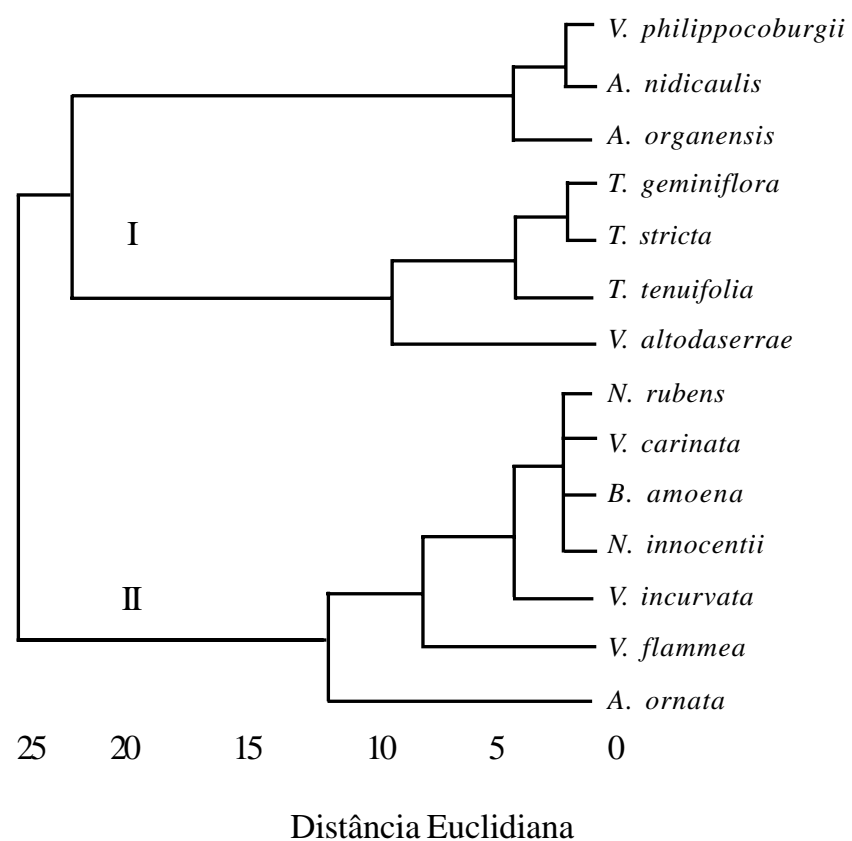

Figura 4. Agrupamento das espécies de bromélias ornitófilas do Parque Estadual Intervales (Ribeirão Grande, SP, Brasil), pela similaridade das espécies de beija-flores que as visitam (I - principalmente visitadas por Trochilinae; II predominantemente visitadas por Phaethornitinae.

Figure 4. Ornitophilous bromeliad groups in the Parque Estadual Intervales (Ribeirão Grande, SP, Brasil), according to similarity of hummingbird visitors ( $\mathrm{I}-$ mainly visited by Trochilinae visitors; II - mainly visited by Phaethornitinae). 
Dessa forma, as bromeliáceas devem ser consideradas fundamentais para a manutenção local da fauna de beija-flores residentes na Mata Atlântica, beneficiando não somente estas aves como também as próprias bromeliáceas ornitófilas e outras espécies da comunidade que utilizam estas aves como seus vetores de pólen.

Neste estudo, cerca de $70 \%$ das espécies de bromélias floresceram durante a estação chuvosa, período no qual também foi verificado maior número de indivíduos floridos. Fischer \& Araujo (1995) observaram proporção semelhante neste período em região estuarina do Estado de São Paulo, assim como Sazima et al. (1995) observaram em todas as comunidades de vegetais ornitófilos com que trabalharam. Essa tendência assemelha-se ao encontrado por Wolf et al. (1976) com flores polinizadas por beija-flores em floresta estacional da América Central e corrobora o padrão esperado em ambientes tropicais, onde os fatores climáticos mais favoráveis, como temperatura e pluviosidade maiores, resultam em uma alta produtividade primária (Pandey \& Singh 1992). A maior disponibilidade de flores ornitófilas como recurso na estação chuvosa também é coincidente com o período de reprodução da maioria de espécies de beija-flores (Sick 1984), o que demonstra a estreita inter-relação entre estes organismos.

Vriesea carinata apresentou pico de floração durante o mês de junho. Em outra área da Mata Atlântica, Araujo et al. (1994) observaram um período de floração de V. carinata mais longo, de abril a outubro, com o pico em julho e agosto. Comparado aos dados registrados por Fischer (1994), Araujo (1996) e Buzato et al. (2000), com Bromeliaceae da Mata Atlântica em São Paulo, verificou-se que Nidularium innocentii, Aechmea nudicaulis, A. organensis, Vriesea altodaserrae, $V$. incurvata, Tillandsia stricta, T. tenuifolia e $T$. geminiflora apresentaram, no PEI, período e pico de floração diferentes das áreas estudadas por aqueles autores. Essas diferenças quanto ao início e extensão do período de floração das mesmas espécies em áreas diversas indicam que fatores ambientais são mais importantes para a fenologia destas espécies que fatores intrínsecos, como relações filogenéticas e história evolutiva do grupo (Kochmer \& Handel 1986).

Todas essas espécies apresentaram atributos da síndrome da ornitofilia (Faegri \& Pijl 1980), como: inflorescências expostas, flores tubulosas, antese diurna, cores conspícuas ou contrastantes, néctar com concentração entre $20 \%$ e $32 \%$, inodoras, estigma e anteras afastadas dos nectários e posicionados para o contato com as aves e ausência de plataforma de pouso.

Feinsinger (1983) e Fischer (1994) encontraram alta correlação positiva entre tamanho de corola e concentração de solutos (açúcares) no néctar. Isso pode estimular, em flores de corola longa, a maior freqüência de beija-flores de bico longo, uma vez que a recompensa é melhor. No entanto, essa correlação entre tamanho do tubo da corola e concentração de néctar, ainda que positiva, não foi significativa nas bromélias ornitófilas deste estudo. A correlação positiva entre o tamanho do tubo da corola com o volume de néctar produzido nas espécies aqui estudadas corrobora a idéia de que flores com corolas de tubo longo selecionam visitantes de bico mais longo conferindo-lhes melhor recompensa (Arizmendi \& Ornelas 1990).

Espera-se que haja alta correlação entre o comprimento dos bicos dos beija-flores e o comprimento da corola das flores que visitam, pois corolas longas tendem a impedir que visitantes de bico curto alcancem o néctar contido na câmara nectarífera no fundo do tubo, selecionando, desta forma, aves com bico mais longo (Fenster 1991). Neste estudo, esta correlação não foi significativa. Este resultado provavelmente foi influenciado pelo fato de que espécies de bico longo também visitaram espécies de bromélias de corola curta.

Billbergia amoena pode apresentar mimetismo intrapopulacional, pois apenas algumas flores em cada indivíduo produzem néctar. Nesse caso, flores sem néctar seriam visitadas por beija-flores que poderiam confundi-las com aquelas que efetivamente produzem néctar (modelos). Espécies com flores em padrões automiméticos também foram descritas em regiões temperadas (Brown \& Kodric-Brown 1979).

Entre os beija-flores, apenas um representante da sub-família Phaethornithinae foi registrado (Phaethornis eurynome), enquanto as demais espécies pertencem à sub-família Trochilinae. Esses dados, assim como os de Buzato et al. (2000), corroboram Snow \& Snow (1986), que sugeriram que os trochilíneos são mais abundantes em altitudes mais elevadas.

O longo período entre as visitas de Phaethornis eurynome às flores, somada ao fato desta ave não ter permanecido próxima às flores que visitava, sugere que este apresente técnica de forrageamento do tipo "linha de captura" ou seja, forrageia efetuando um longo roteiro de visitas, não demarcando território definido. Esta estratégia de forrageamento é típica das espécies da sub-família Phaethornithinae (Gottsberger 1986, Tiebout III 1993). No entanto, durante a floração de Vriesea altodaserrae, Phaethornis eurynome apresentou estratégia de forrageamento do tipo territorialista durante 
o período de maior produção de nectar (figura 3), embora não tenha apresentado nenhuma interação agonística interespecífica. Essa alteração temporária de comportamento tem sido reportada em outros estudos (Stiles 1978, Feisinger \& Colwell 1978, Canela \& Sazima 2003). Provavelmente, a alta densidade de flores que produziam grande volume de néctar e a ausência de outras espécies competidoras influenciou esse comportamento em Phaethornis eurynome durante aquele período.

Em relação ao agrupamento das espécies de bromélias quanto à similaridade de seus visitantes florais, no primeiro conjunto de bromélias foram mais comuns os beija-flores da sub-família Trochilinae como agentes polinizadores (figura 4, conjunto I). Entre as espécies polinizadas exclusivamente por Thalurania glaucopis, ou que tenham tido este troquilídeo como o visitante mais freqüiente, foi observado que seus picos de floração não foram coincidentes (figura 1), o que pode evitar competição pelos beija-flores, diminuindo a probabilidade de mistura de pólen de diferentes espécies no corpo das aves, o que reduziria a transferência correta de pólen.

Todas as espécies de bromeliáceas do conjunto I são heliófilas e a predominância de visitas de beija-flores troquilíneos foi esperada, pois as espécies dessa subfamília, ao contrário de Phaethornis eurynome, forrageiam em locais mais abertos (Piratelli 1997).

Tillandsia geminiflora e T. stricta apresentaram alto grau de similaridade, ou seja, partilharam quase os mesmos agentes polinizadores, sendo Amazilia versicolor o mais freqüente deles. São plantas que podem ocorrer em ambientes semelhantes, porém seus períodos de pico de floração também não foram coincidentes. A relativa semelhança entre essas duas plantas (flores azuis arroxeadas e brácteas rosadas) pode ainda reforçar nos beija-flores uma imagem de procura das flores, aumentando as chances de serem visitadas, como sugeriram Araujo et al. (1994).

O segundo conjunto de bromélias (figura 4, conjunto II) foi formado pelas espécies preferencialmente esciófilas, sendo Phaethornis eurynome seu único ou o mais freqüente agente polinizador (figura 3). Nesse conjunto de espécies foi observado um padrão de floração seqüencial e contínuo, de novembro a maio. Esse padrão fenológico ocorreu também em florestas da América Central nas plantas polinizadas por Phaethornithinae (Stiles 1978). As bromeliáceas que foram exclusivamente visitadas por Phaethornis eurynome e são todas esciófilas, podendo ocorrer no mesmo ambiente. Essas espécies, porém, apresentam picos de floração em períodos distintos (figura 1). Assim, a competição por polinizadores entre as bromeliáceas que ocorrem na área de estudo é minimizada, como também a possibilidade de hibridação interespecífica.

Ainda dentro desse segundo conjunto de plantas, observaram-se espécies (como Vriesea incurvata, V. flammea e Aechmea ornata) que foram visitadas por outras espécies de beija-flores, tendo Phaethornis eurynome como seu principal visitante (figura 3). A primeira delas, Vriesea incurvata, é uma espécie esciófila, que apresentou floração durante quase toda a estação chuvosa, com pico em janeiro e fevereiro. No entanto, esteve restrita a ambientes bastante úmidos, próximos a cursos d'água, possibilitando as visitas de Phaethornis eurynome, que forrageia preferencialmente em ambientes sombreados (Piratelli 1997). Já Vriesea flammea e Aechmea ornata diferiram em seus períodos de pico de floração (figura 1) e também ocorreram em estratos vegetacionais distintos (a primeira no estrato médio da vegetação e em borda de mata e a última, no dossel). Apesar de ambas serem heliófilas podiam ocorrer sombreadas por copas das árvores, possibilitando as visitas constantes de Phaethornis eurynome.

A deposição de pólen em diversos locais do corpo dos beija-flores poderia ser um mecanismo para evitar a mistura de pólen das diferentes espécies. No entanto, dada a estrutura mais comum das flores destas bromélias, na qual as anteras ocorrem no interior da corola tubulosa, o bico dos beija-flores tendeu a ser o local mais freqüente de impregnação de pólen, o que também foi observado por Fischer (1994), Sazima et al. (1995, 1996), Araujo (1996) e Buzato et al. (2000). Assim, o período de floração e tipos distintos de ambientes onde ocorreram as bromeliáceas pareceram ser os principais meios de se evitar a competição por vetores de pólen.

Agradecimentos - À Capes, pelo apoio financeiro; à Fundação para a Conservação e Produção Florestal do Estado de São Paulo e ao Parque Estadual Intervales, pelo apoio logístico; aos Departamentos de Botânica (Unicamp) e de Ciências Biológicas (UEFS); ao Dr. Wesley R. Silva, à Dra. Silvana Buzato, à Dra. Julie H.A. Dutil e ao Dr. Marco Aurélio Pizo, pelas valiosas críticas; à Dra. Maria da Graça L. Wanderley, pela identificação de algumas bromélias deste estudo; aos companheiros do Depto. de Botânica/Unicamp e DCBio/UEFS pela ajuda providencial nas diversas fases deste estudo; e a Nívea Mara Ribeiro Rodrigues, pelo precioso auxílio nos trabalhos de campo e acompanhamento deste projeto; aos revisores anônimos, pelas críticas e sugestões. 


\section{Referências bibliográficas}

ALTMANN, S.A. 1974. Observacional study of behavior: sampling methods. Behavior 49:227-265.

ARAUJO, A.C. 1996. Beija-flores e seus recursos florais numa área de planície costeira do litoral norte de São Paulo. SP. Dissertação de mestrado, Universidade Estadual de Campinas, Campinas.

ARAUJO, A.C., FISCHER, E.A. \& SAZIMA, M. 1994. Floração sequiencial e polinização de três espécies de Vriesea (Bromeliaceae) na região da Juréia, sudeste do Brasil. Revista Brasileira de Botânica 17:113-118.

ARAUJO, A.C., FISCHER, E. \& SAZIMA, M. 2004. As bromélias na região do Rio Verde. In Estação Ecológica Juréia-Itatins: Ambiente físico, flora e fauna (O.A.V. Marques \& W. Duleba, eds.). Editora Holos, Ribeirão Preto.

ARIZMENDI, M.C. \& ORNELAS, J.F. 1990. Hummingbirds and their floral resources in tropical dry forest in Mexico. Biotropica 22:172-180.

BENZING, D.H. 1980. The biology of the bromeliads. Mad River Press, Eureka.

BROWN, J.H. \& KODRIC-BROWN, A. 1979. Convergence, competition, and mimicry in a temperate community of hummingbird-pollinated flowers. Ecology 60:1022-1035.

BUZATO, S., SAZIMA, M. \& SAZIMA, I. 2000. Hummingbird-pollinated floras at three Atlantic forest sites. Biotropica 32:824-841.

CANELA, M.B.F. \& SAZIMA, M. 2003. Aechmea pectinata: a hummingbird-dependent Bromeliad with inconspicuous flowers from the rainforest in Southeastern Brazil. Annals of Botany 92:731-737.

DAFNI, A. 1992. Pollination Ecology. Oxford University Press, Oxford.

FAEGRI, K. \& PIJL, L. 1980. The principles of pollination ecology. Pergamon Press, New York.

FEINSINGER, P. 1983. Variable nectar secretion in a Heliconia species pollinated by hermit hummingbirds. Biotropica 15:48-52.

FEINSINGER, P. \& COWELL. R.K. 1978. Community organization among Neotropical nectar feeding birds. American Zoologist 18:779-795.

FENSTER, C.B. 1991. Selection on floral morphology by hummingbirds. Biotropica 23:98-101.

FISCHER, E.A. 1994. Polinização, fenologia e distribuição espacial de Bromeliaceae numa comunidade de Mata Atlântica, litoral sul de São Paulo. Dissertação de mestrado, Universidade Estadual de Campinas, Campinas.

FISCHER, E.A. \& ARAUJO, A.C. 1995. Spatial organization of a bromeliad community in the Atlantic Rainforest, South-Eastern Brazil. Journal of Tropical Ecology 11:559-567.

GARDNER, C.S. 1986. Inferences about pollination in Tillandsia (Bromeliaceae). Selbyana 9:76-87.
GOTTSBERGER, G. 1986. Some pollination strategies in Neotropical savannas and forests. Plant Systematic Evolution 152:26-45.

KAERNS, C.A. \& INOUYE, D.W. 1993. Techniques for pollination biologists. University Press of Colorado, Niwot.

KOCHMER, J.P. \& HANDEL, S.N. 1986. Constraints and competition in the evolution of flowering phenology. Ecological Monographs 56:303-325.

KÖEPEN, W. 1948. Climatología. Fondo de Cultura Econômica, Mexico.

MACHADO, C.G. 1999. Composição e estrutura de bandos mistos de aves na Mata Atlântica do alto da Serra do Paranapiacaba, SP. Revista Brasileira de Biologia 1:62-65.

MAGURRAN, A.E. 1988. Ecological diversity and its measurement. Croom Helm, Sydney.

MORELLATO, L.P.C. \& LEITÃO FILHO, H.F. 1992. Padrões de frutificação e dispersão na Serra do Japi. In História Natural da Serra do Japi: ecologia e preservação de uma área florestal no Sudeste do Brasil (L.P.C. Morellato, org.). Editora da Unicamp, Campinas, p.112-140.

NASCIMENTO, F.H. 1994. A sucessão secundária inicial na Mata Atlântica sobre a Serra de Paranapiacaba, Ribeirão Grande, SP. Dissertação de mestrado, Universidade de São Paulo, São Paulo.

NEWSTROM, L.E., FRANKIE, G.W. \& BAKER, H.G. 1994. A new classification for plant phenology based on flowering patterns in Lowlands tropical rain forest trees at La Selva, Costa Rica. Biotropica 26:141-159.

PANDEY, C.B. \& SINGH, S.J. 1992. Rainfall and grazing effects on net primary productivity in tropical savanna India. Ecology 73:2007-2021.

PIRATELLI, A.J. 1997. Comportamento alimentar de beijaflores em duas espécies de Hippeastrum Herb. (Amaryllidaceae). Revista Brasileira de Biologia 57:261-273.

PONÇANO, W.L. 1981. Mapa geomorfológico do Estado de São Paulo. v.1. Secretaria da Indústria, Comércio e Tecnologia do Estado de São Paulo, São Paulo.

POULIN, B., LEFEBVRE, G. \& MCNEIL, R. 1992. Tropical avian phenology in relation to abundance and exploitation of food resources. Ecology 73:2295-2309.

REITZ, R. 1983. Bromeliáceas e a malária-bromélia endêmica. In Flora ilustrada catarinense (R. Reitz, ed.). Herbário Barbosa Rodrigues, Itajaí.

SAZIMA I., BUZATO, S. \& SAZIMA, M. 1995. The sawbilled hermit Ramphodon naevius and its flowers in southeastern Brazil. Journal of Ornithology 136:195-206.

SAZIMA I., BUZATO, S. \& SAZIMA, M. 1996. An assemblage of hummingbird-pollinated flowers in Montane Forest in Southeastern Brazil. Botanica Acta 109:149-160.

SAZIMA, I., VOGEL, S. \& SAZIMA, M. 1989. Bat pollination of Encholirium glaziovii, a terrestrial bromeliad. Plant Systematic Evolution 168:167-179 
SICK, H. 1984. Ornitologia brasileira: uma introdução. Universidade de Brasília, Brasília, DF.

SNOW, D.W. \& SNOW, B.K. 1980. Relationships between hummingbirds and flowers in the Andes of Colombia. Bulletin of the British Museum of Natural History (Zoology) 38:105-139.

SNOW, D.W. \& SNOW, B.K. 1986. Feeding ecology of hummingbirds in the Serra do Mar, southeastern Brazil. El Hornero 12:286-296.

SNOW, D.W. \& TEIXEIRA, D.L. 1982. Hummingbirds and their flowers in the coastal montains of southeastern Brazil. Journal of Ornithology 123:446-450.

SOKAL, R.R. \& ROHLF, F.J. 1981. Biometry. Freeman Company, San Francisco.

SSPS. 1983.Statistical package for social sciences - user's guide. McGraw-Hill, Chicago.
STILES, F.G. 1978. Temporal organization of flowering among the hummingbird foodplants of a tropical wet forest. Biotropica 10:194-210.

TALORA, D.C. \& MORELLATO, L.P.C. 2000. Fenologia de espécies arbóreas em floresta de planície litorânea do sudeste do Brasil. Revista Brasileira de Botânica 23:13-26.

TIEBOUT III, H.M. 1993. Mechanisms of competition in tropical hummingbirds: metabolic costs for loosers and winners. Ecology 74:405-418.

WASER, N.M. \& REAL, L.A. 1979. Effective mutualism between sequentially flowering plant species. Nature 281:670-672.

WOLF, L.L., STILES, F.G. \& HAINSWORTH, F.R. 1976. Ecological organization of a tropical, highland hummingbird community. Journal of Animal Ecology 32:349-379. 